DOI: http://dx.doi.org/10.37253/jad.v2i2.4969

\title{
Penerapan Konsep Bangunan Pintar Pada New Media Tower Universitas Multimedia Nusantara
}

\author{
${ }^{1}$ Arianto Dwi Putro, ${ }^{2}$ Lutfi Prayogi S.Ars M.Urb Plan \\ ${ }^{1}$ Universitas Muhammadiyah Jakarta, Jakarta, ${ }^{2}$ Universitas Muhammadiyah Jakarta, Jakarta. \\ ariantodwiputro@gmail.com ${ }^{1}$
}

\author{
Informasi Naskah \\ Diterima: 31/05/2021; Disetujui terbit: 22/06/2021; Diterbitkan: 31/12/2021; \\ http://journal.uib.ac.id/index.php/jad
}

\begin{abstract}
ABSTRAK
Pada saat ini dunia telah mengalami perkembangan yang luar biasa salah satunya dalam aspek teknologi. Teknologi saat ini sudah sangat canggih termasuk dalam berarsitektur. Hal tersebut menjadi persaingan dalam melengkapi kelengkapan fasilitas bangunan. Demi tercapainya sebuah bangunan yang hemat energi dan ramah lingkungan. Sistem kontrol dan sensor dalam bentuk teknologi dapat mempengaruhi sistem kerja bangunan sehingga dapat menghasilkan bangunan yang memiliki teknologi canggih. Tujuan dari penelitian ini adalah menjadikan sebuah wawasan dalam merancang bangunan dengan pendekatan bangunan pintar untuk menghasilkan bangunan yang hemat energi, memudahkan pengguna bangunan, menjaga keamanan bangunan, dan berkelanjutan. Metode penelitian yang dilakukan adalah dengan metode deskriptif. Objek penelitian ini dilakukan pada bangunan fasilitas pendidikan yaitu Universitas Multimedia Nusantara. Bangunan pintar diterapkan melalui beberapa prinsip dan terdiri dari berbagai aspek yang berkaitan dengan perangkat mekanikal dan elektrikal serta sistem keamanan pada bangunan. Seluruh perangkat tersebut dikontrol dalam sebuah sistem otomasi bangunan sehingga bangunan tersebut menghasilkan bangunan yang hemat energy dan ramah lingkungan. Bangunan pintar juga memiliki beberapa element arsitektural sebagai element yang menunjang kinerja dari sistem bangunan pintar itu sendiri agar dapat bekerja secara optimal dalam mewujudkan bangunan yang hemat energi.
\end{abstract}

Kata Kunci: Arsitektur; Universitas Multimedia Nusantara; Bangunan Pintar; Sistem Otomasi Bangunan

\begin{abstract}
At this time the world has experienced extraordinary developments, one of which is in the technological aspect. The technology is currently very sophisticated, including in architecture. This is a competition in completing the complete building facilities. In order to achieve an energyefficient and environmentally friendly building. Control systems and sensors in the form of technology can affect the building work system so that it can produce buildings that have advanced technology. The purpose of this research is to provide an insight into designing buildings with a smart building approach to produce buildings that are energy efficient, make it easier for building users, maintain building security, and are sustainable. The research method used is descriptive method. The object of this research was carried out in the building of educational facilities, namely Multimedia Nusantara University. Smart building is applied through several principles and consists of various aspects related to mechanical and electrical devices and security systems in buildings. All of these devices are controlled in a building automation system so that the building produces energy-efficient and environmentally friendly buildings. Smart buildings also have several architectural elements as elements that support the performance of the smart building system itself so that it can work optimally in realizing energy-efficient buildings.
\end{abstract}

Keyword: Architecture; Multimedia Nusantara University; Smart Building; Building Automation Systems 


\section{PENDAHULUAN}

Negara Indonesia memberikan layanan yang layak untuk pendidikan kepada seluruh warga negara Indonesia. Pendidikan adalah sebuah sarana untuk mengembangkan ilmu pengetahuan agar terciptanya kemujuan bangsa. Sehingga Indonesia mampu menciptakan generasi generasi yang memiliki kemampuan kemajuan dari berbagai bidang pendidikan (social, ekonomi dan teknologi). Dalam prosesnya pendidikan tidaklah lepas dari sosok guru. Semakin ketat persaingan dunia yang mempengaruhi kelengkapan fasilitas bangunan sebagai tuntutan masyarakat akan kemudahan, kelengkapan fasilitas, dan kecanggihan dalam segala hal. Bangunan pintar adalah sebuah pendekatan yang memberikan sebuah manfaat baik itu bangunan maupun pengguna dan lingkungan sekitarnya. Bangunan pintar merupakan sebuah prinsip kerja bangunan yang memanfaatkan kecanggihan teknologi yang saling terintegrasi dan menciptakan bangunan yang hemat energy, aman, nyaman dan berkelanjutan. "Smart building adalah bangunan yang menggunakan Building Automation System (BAS) atau disebut juga dengan Intelligent Building System (IBS). Dalam dunia berarsitekur, smart building adalah sebuah sebuah konsep bangunan dengan aspek utilitas yang meliputi fungsi servis baik dari komunikasi, otomatisasi bangunan, dan mampu menyesuaikan dengan aktivitas penggunanya. Bangunan pintar memiliki sebuah teknologi yang mengedepankan hemat energy dan efektifitas dalam penerapannya baik dalam perencanaan lingkungan maupun bangunan itu sendiri.

Oleh sebab itu bangunan pintar dalam pembangunan fisik sangatlah penting untuk memenuhi kebutuhan bangunan bukan hanya memfasilitasi agar terciptanya kenyamanan dan kemudahkan bagi pengguna saja akan tetapi merupakan hal global dalam memajukan negara agar menjadi negara yang maju dan lebih baik.

\section{Kajian Pustaka}

Menurut Buckman dkk, dalam jurnal (Hoy., 2016) menjelaskan "tentang perbedaan antara bangunan pintar dan cerdas."Mereka menjelaskan perkembangan teknologi bangunan dari "primitif," menjadi "sederhana" hingga "Otomatis" menjadi "cerdas" hingga "gedung pintar". Bangunan pintar mengumpulkan data tentang bagaimana dan kapan sebuah bangunan dibangun digunakan dan memberikan gambaran tentang status suatu bangunan.

Ghaffarianhoseini menjelaskan Dalam jurnal ilmiah berjudul "Analysis of recent interpretations from an international perspective", perbedaan sudut pandang yang nyata ketika definisi (Buckman., Alex., Mayfield., \& Stephen Beck, 2014), adalah kontras yang menganggap kecerdasan sebagai salah satu dari komponen bangunan pintar, dengan (Ghaffarianhoseini, et al., 2016) yang menganggap kepintaran itu saja sebuah indikator bangunan cerdas, tetapi yang lebih penting adalah pada dasarnya mereka mewakili tujuan yang sama.

Menurut Coggan (1997), "Bangunan cerdas menggunakan komputer secara ekstensif dan berhubungan dengan teknologi tinggi. Bahkan, Nation Academy of Sciences di Washington, DC memiliki komite yang berhubungan dengan elektronik yang di sempurnakan bangunan. Ini melihat benda-benda elektronik yang dibagi empat kelompok, diantaranya :

- Efesiensi energy

- Lifesafety system 
- System telekomunikasi

- Kerja otomatisasi

\section{Manfaat Bangunan Pintar}

Manfaat Bangunan Pintar menurut (Pramanik, Bulbul, Saurabh, Tanmoy, \& Simar, 2019) adalah Merancang infrastruktur pintar dengan kolaborasi perangkat keras dan perangkat lunak untuk yang baru atau bangunan yang ada memastikan manfaat berikut: Menurunkan biaya, system yang sepenuhnya terintegrasi dan otomatis sehingga memudahkan dalam maintenance bangunan, meningkatkan kepuasan, kenyamanan dan produktivitas bagi penghuni bangunan, Efesiensi energy karena meminimalisir pemakaian energy yang berlebihan pada system bangunan, system deteksi kesalahan otomatis yang meningkatkan keamanan dalam bangunan, dan Managemen yang mudah karena seluruh data dalam bangunan terinput dalam teknologi.

\section{Prisip Bangunan Pintar}

Menurut (Pramanik, Bulbul, Saurabh, Tanmoy, \& Simar, 2019) dalam jurnal ilmiah yang berjudul "Green Smart Building: Requisites, Architecture, Challenges, and Use Cases" Komponen Utama Bangunan Pintar menekankan upaya multidisiplin, hemat biaya, hemat energi untuk berasimilasi dan mengoptimalkan struktur bangunan, sistem, pelayanan dan pengelolaan yang produktif, responsive suasana nyaman dan ramah lingkungan bagi penghuninya.

Konsep bangunan pintar memiliki beberapa Aspek penerapan didalam bangunan diantaranya:
a. Bangunan Pintar Aspek Pencahayaan
b. Bangunan Pintar Aspek Penghawaan
c. Bangunan Pintar Aspek Pemipaan (Daur Ulang)
d. Bangunan Pintar Aspek Transportasi
e. Bangunan Pintar Aspek Elektrikal
f. Bangunan Pintar Aspek Keamanan

\section{Metode Penelitian}

Metode Penelitan yang digunakan dalam analisa konsep bangunan pintar adalah medote kualitatif yang disajikan dalam bentuk deskripsi. Tujuan penelitian kualitatif ini dikarenakan pemahaman dalam penerapan aspek bangunan pintar pada bangunan fasilitas pendidikan yang dapat disajikan dengan bentuk deskripsi. Langkah-langkah dalam penelitian ini sebagai berikut :

1. Mengumpulkan data primer

Data yang didapat dari berbagai sumber baik jurnal maupun buku serta mencari data-data studi kasus dari sumber-sumber diantaranya: website arsitek perencana studi kasus dan website universitas dari studi kasus.

2. Pemilihan data

Data yang terkumpul kemudian dipilih dan ditata terkait dengan data-data yang relevan.

3. Analisis data

Pengolahan dari data tersebut kemudian dianalisis berdasarkan teori dari refrensi melalui 
sketsa-sketsa atau diagram dalam proses analisisnya. Sehingga mendapatkan hasil dan kesimpulan terkait analisa konsep bangunan pintar.

\section{Objek Penelitian}

Universitas Multimedia Nusantara adalah sebuah universitas yang berdiri sejak tahun 2005. Universitas ini Berhasil Meraih Juara Pertama Energy Efficient Building kategori Tropical Building dalam Asean Energy Award pada tahun 2014. Multimedia Nusantara (UMN) berkomitmen untuk membangun gedung-gedung perkuliahan yang hemat energi.

Kampus Universitas Multimedia Nusantara berlokasi di kawasan perumahan Summarecon Gading Serpong, Tangerang. Lokasi tersebut diapit oleh 2 jalan tol yaitu Tol Jakarta-Merak dan Tol JORR-Serpong BSD. Gedung Universitas Multimedia Nusantara ini, dibangun di lahan seluas delapan hektar yang lokasinya di kelilingi oleh perumahan dan kawasan komersial seperti perkantoran, ruko, mal, hotel, dan rumah sakit. Berikut ini gambar lokasi Kampus Universitas Multimedia Nusantara :

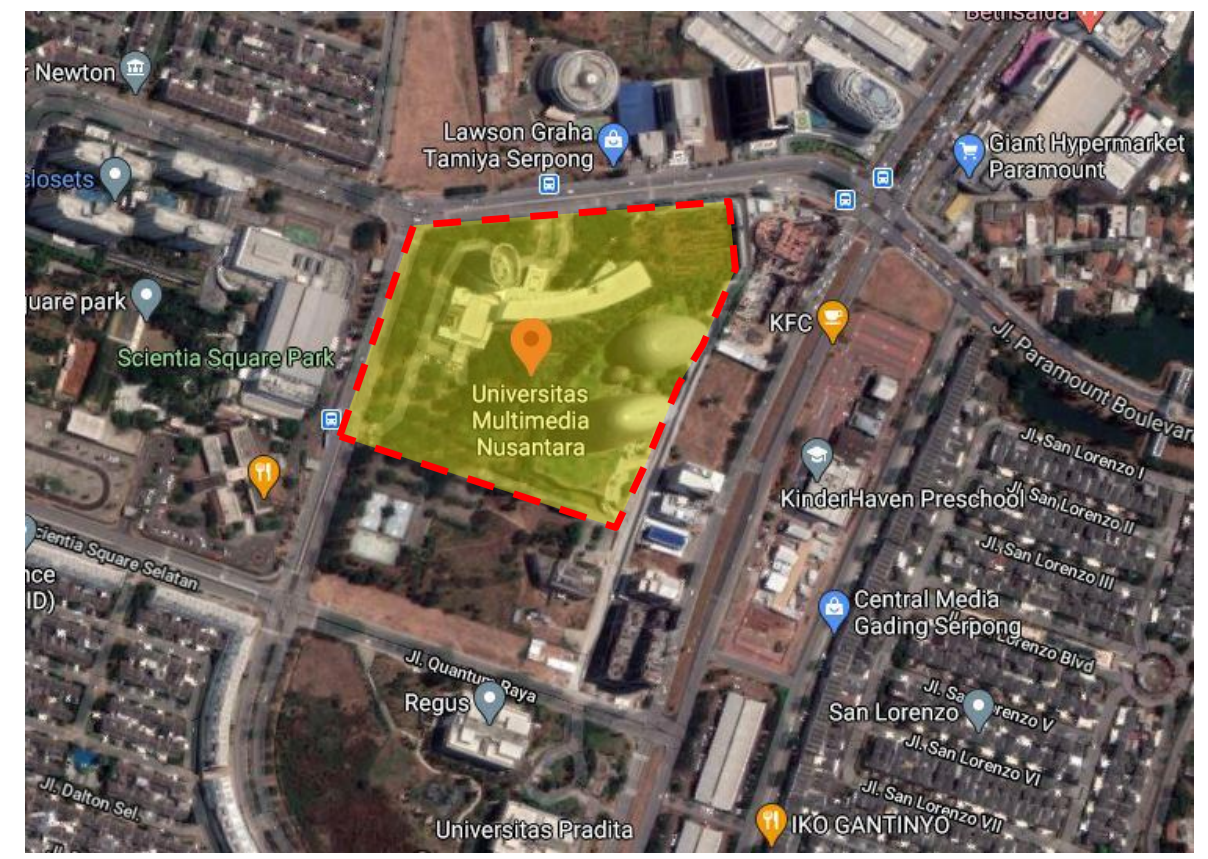

Gambar 1. Peta Lokasi UMN

Sumber: Google Maps, 2021

\section{Hasil dan Pembahasan}

Konsep bangunan pintar memiliki beberapa Aspek penerapan didalam bangunan. Berikut ini adalah penerapan dari beberapa aspek bangunan pintar pada bangunan universitas multimedia nusantara.

\section{Sistem Utilitas Bangunan Pintar Aspek Pencahayaan}

Sistem Utilitas Bangunan Pintar Aspek Pencahayaan adalah sebuah system utilitas yang memanfaatkan pencahayaan buatan seperti lampu. Cahaya Lampu yang dibuat harus mengcover seluruh ruangan yang ada dalam bangunan. Titik lampu yang dipasang harus 
menyebar secara efektif dan efisien ke setiap sudut ruangan. Sistem ini tidak hanya bergantung kepada pencahayaan buatan seperti lampu, tetapi juga kepada pengaturan masuknya cahaya alami kedalam bangunan. Cahaya alami yang masuk kedalam bangunan dapat mengatur banyaknya penggunaan lampu sehingga bisa lebih hemat energi listrik yang digunakan pada siang hari. Dengan begitu biaya operasional bangunan bisa lebih hemat sehingga pengeluaran lebih efektif dan efisien.

Bangunan Universitas multimedia nusantara memiliki ruang-ruang kelas yang banyak dan berorientasi keseluruh arah. Universitas Multimedia Nusantara memiliki banyak bukaan pencahayaan dan pengoptimalan cahaya matahari masuk kedalam bangunan dengan façade ganda.

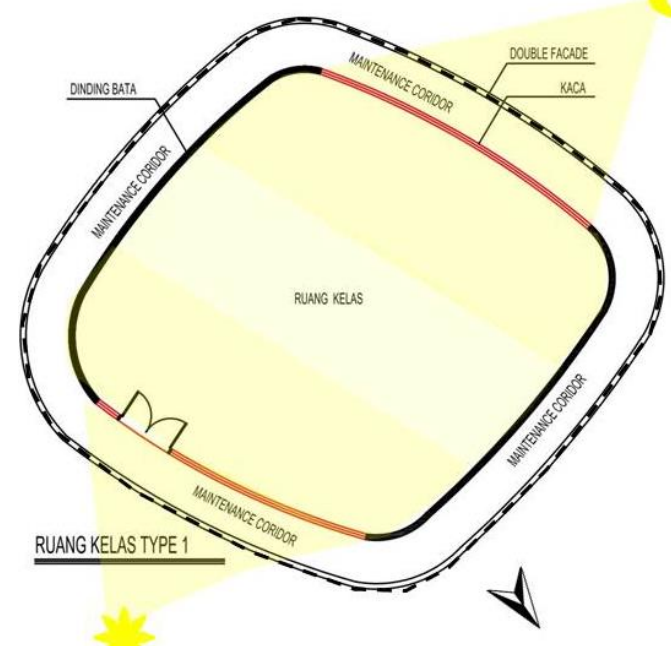

Gambar 2. Denah Ruang Kelas UMN Gedung C Sumber: Dokumen Pribadi, 2021

Pada Gambar 2. Universitas multimedia nusantara memiliki ruang kelas yang memanfaatkan bukaan jendela dengan ukuran lebar pada arah matahari timur laut dan barat daya. Bukaan jendela yang lebar pada ruangan kelas memiliki ruang hubung yang digunakan sebagai maintenance corridor dan terletak diantara bukaan jendela ke parimeter kulit bangunan. Ruang hubung atau maintenance corridor tersebut berfungsi sebagai space atau ruang yang meminimalisir radiasi matahasi masuk ke ruang kelas. Sebuah pencahayaan cross ventilation yang diterapkan pada ruang kelas memberikan efek maksimal pencahayaan alami didalam ruangan. Upaya lainnya dalam meminimalisir radiasi matahari pada bangunan universitas multimedia nusantara adalah dengan penerapan façade ganda atau secondary skin. Façade ganda yang diaplikasikan bangunan universitas multimedia nusantara ini menggunakan material Aluminium Composite Panel Perforeted. Double Façade yang terapkan bangunan ini merupakan façade aktif yang bagian facadenya memiliki lubanglubang dengan ukuran berbeda-beda yang sudah didesain untuk masuknya cahaya dan meminimalisir radiasi matahari. 


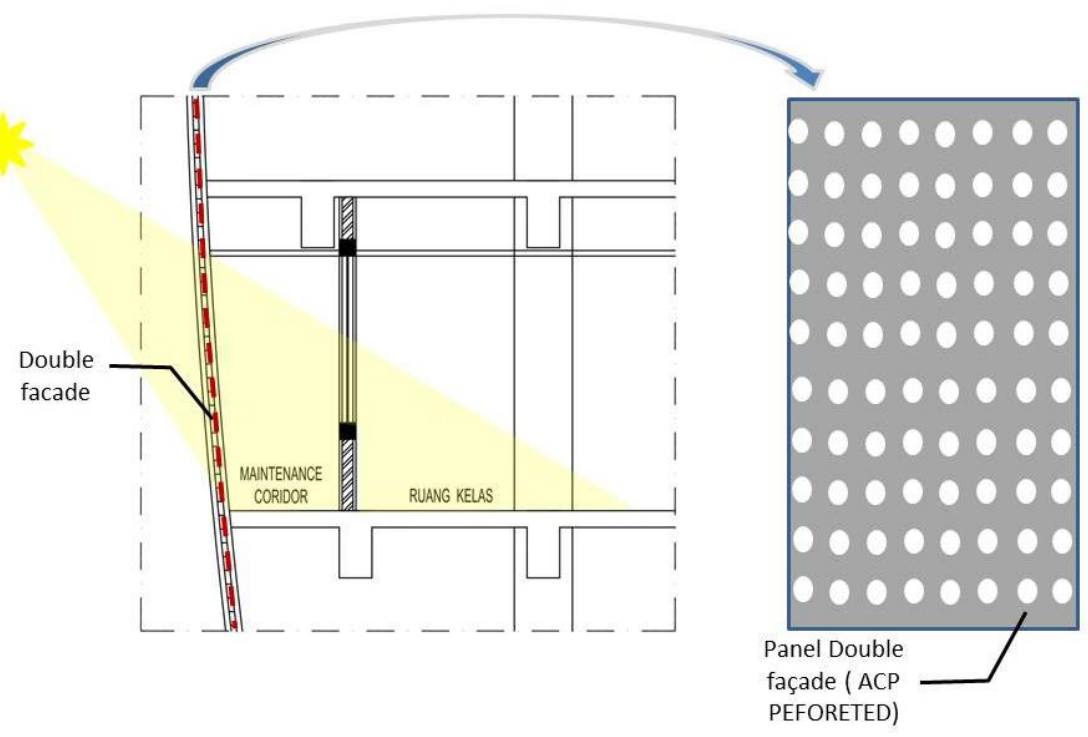

Gambar 3. Potongan Ruang Kelas UMN Gedung C Sumber: Dokumen Pribadi, 2021

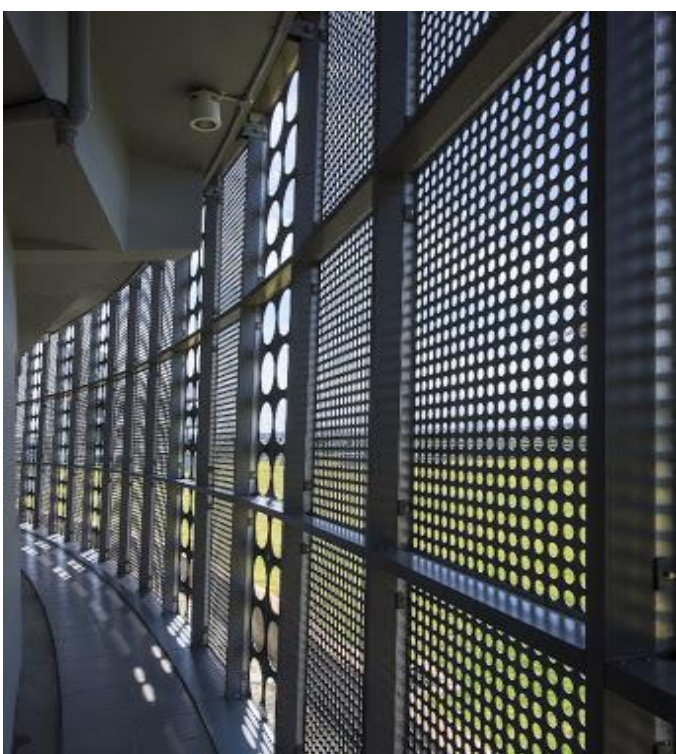

Gambar 4. Foto Facade ACP UMN Gedung C Sumber: Home.id, 2021

Pada gambar 4. Adalah merupakan sebuah pengamplikasian sebuah double façade atau secondary skin pada bangunan universitas multimedia nusantara. Double façade yang menggunakan material aluminium composite panel perforated memberikan sebuah efek shading cahaya matahari yang masuk dari celah lobang-lobang ACP kedalam ruangan yang memiliki bukaan jendela full pada sisi pinggir façade.

Pada bangunan Universitas multimedia nusantara menggunakan cahaya penerangan dari lampu. Lampu yang digunakan oleh bangunan universitas multimedia nusantara adalah lampu LED type T5. Keunggulan dari lampu LED itu sendiri dapat menghemat energy listrik, ekonomis, tahan lama, dan ramah lingkungan atau tidak membahayakan bagi pengguna. Lampu LED tersebut dapat diatur dengan menggunakan teknologi yang terkoneksi serta mampu dikontrol oleh Building Automation System (BAS) dalam penggunaannya sehingga bisa lebih efektif dan hemat energy. 


\section{Sistem Utilitas Bangunan Pintar Aspek Penghawaan}

Sistem Utilitas Bangunan Pintar Aspek Penghawaan adalah sebuah system utilitas yang memanfaatkan penghawaan buatan missal AC yang dibuat harus mengcover seluruh ruangan yang ada dalam bangunan dan dapat terkontrol oleh system otomatis bangunan atau Building Automatic System (BAS). AC yang dipasang harus menyebar secara efektif dan efisien ke setiap sudut ruangan. Sistem ini tidak hanya bergantung kepada penghawaan buatan seperti $A C$, tetapi juga kepada pengaturan masuk keluarnya Udara alami kedalam bangunan dan mengontrol AC agar tidak terbuang sia-sia. Udara alami yang masuk kedalam bangunan dapat mengatur banyaknya AC yang dibutuhkan dalam bangunan sehingga bisa lebih hemat energi listrik. Dengan begitu biaya operasional bangunan bisa lebih hemat sehingga pengeluaran lebih efektif dan efisien.

Sistem Utilitas Bangunan Pintar Aspek Penghawaan yang terjadi distudi kasus bangunan Universitas Multimedia Nusantara ini adalah Ruangan-ruangan kelas yang memiliki banyak bukaan jendela sehingga udara alami dapat masuk kedalam ruangan. Pengaplikasian banyaknya bukaan jendela serta orientasi bukaan jendela pada bangunan ini yang mengarah kesegala arah mataangin. Hal tersebut memungkinkan suhu panas dan debu masuk kedalam bangunan, untuk meminimalisir hal tersebut bangunan ini menggunakan double façade atau secondary skin yang terbuat dari material aluminium composite panel dan dirancang dengan memiliki lubang lubang ukuran yang berbeda-beda.

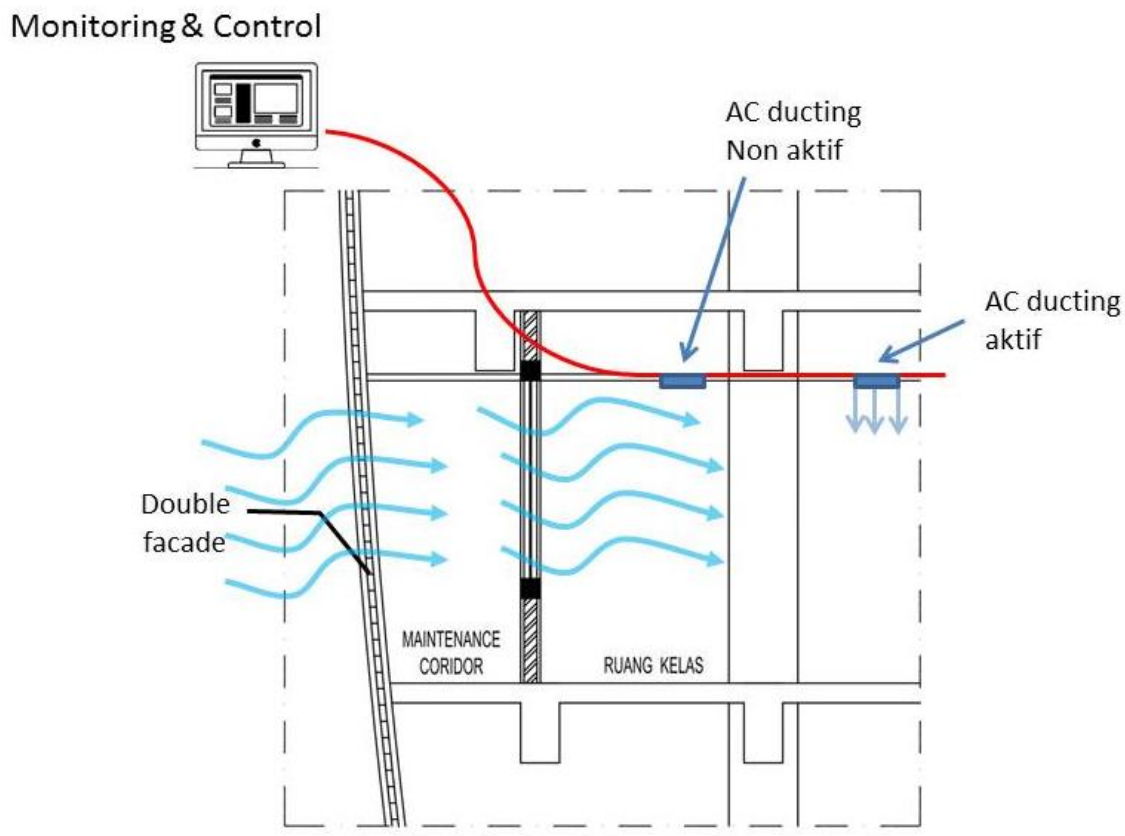

Gambar 5. Potongan Ruang Kelas Analisis Penghawaan UMN Gedung C Sumber: Dokumen Pribadi, 2021

Sistem penghawaan buatan yang digunakan pada bangunan ini adalah system AC ducting atau AC central. AC ducting yang ada pada bangunan universitas multimedia nusantara ini memudahkan dalam maintenance nya serta memberikan kenyamanan bagi mahasiswa yang belajar dan lama beraktivitas didalam ruangan tersebut.

\section{Sistem Utilitas Bangunan Pintar Aspek Pemipaan (Daur Ulang)}


Sistem Utilitas Bangunan Pintar Aspek Pemipaan daur ulang yaitu system pengolahan air bersih, air bekas, air kotor dan air hujan untuk bisa didistribusikan, didaur ulang dan dibuang tanpa mencemari lingkungan sekitar. Hal tersebut merupakan salah satu upaya untuk menghemat biaya dalam penggunaan air dan memanfaatkan hasil air daur ulang tersebut agar dapat bermanfaat layaknya air bersih namun tidak bisa dikonsumsi.

Pengolahan limbah air kotor dan bekas berada diarea basement bangunan UMN. Sistem daur ulang ini memberikan efek penghematan air dan dampak negatif pembuangan limbah secara langsung ke saluran kota. Sistem air daur ulang di UMN terbagi menjadi 3 lokasi yaitu digedung $A$ dan $B$ dijadikan satu lokasi system air daur ulang, Di gedung $C$ satu system air daur ulang dan digedung $D$ satu system air daur ulang,Kapasitas setiap masingmasing gedung berbeda-beda. Kapasitas limbah yang bisa diolah di gedung A sebesar 150 m3, gedung $C$ dan gedung $D$ masing-masing sebesar 300 m3.

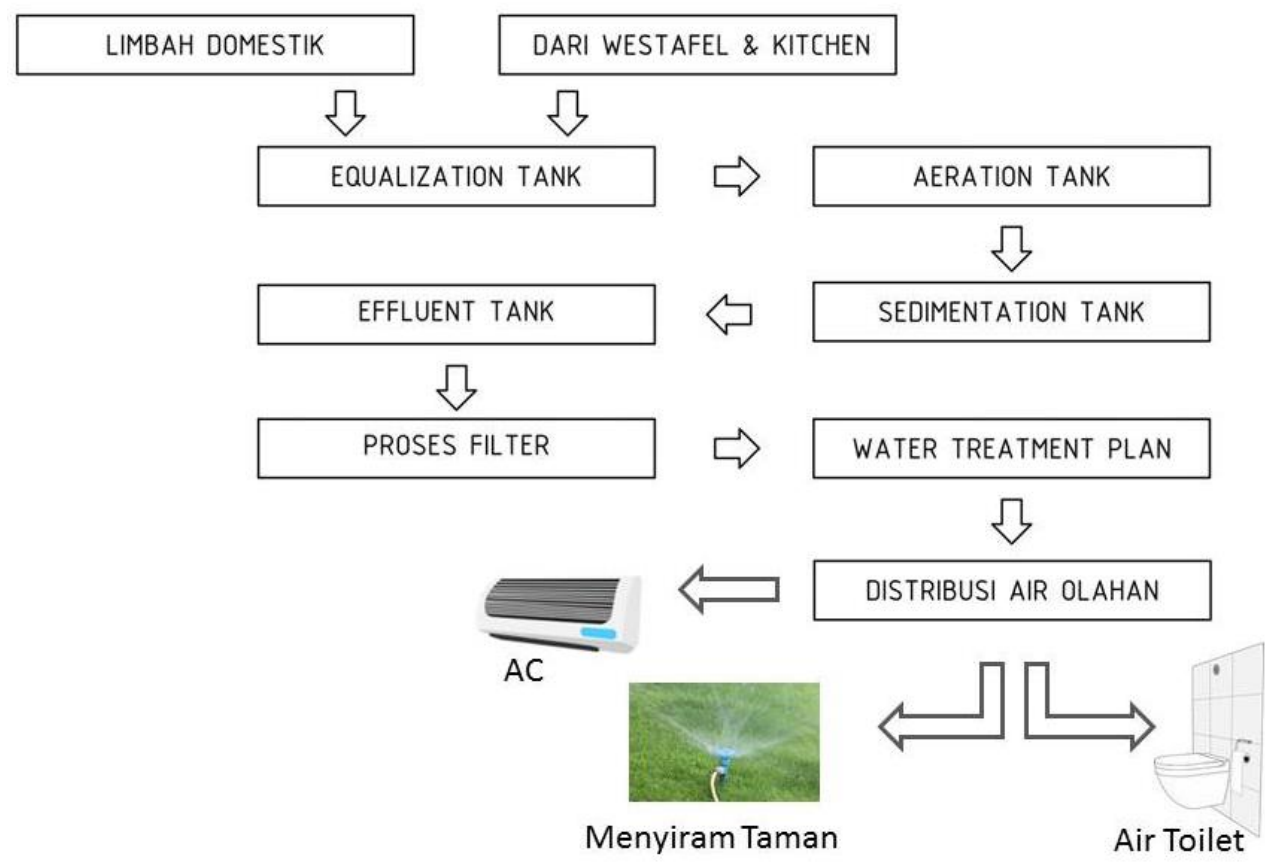

Gambar 6. Sistem STP UMN Gedung C Sumber: Dokumen Pribadi, 2021

Pemanfaatan air hasil dari daur ulang tidak dapat dikonsumsi namun air hasil daur ulang di bangunan universitas multimedia nusantara ini dimanfaatkan untuk kebutuhan yaitu air toilet, menyiram tanaman, dan pendingin ruangan terpusat (AC sentral). UMN memanfaatkan air daur ulang untuk menghemat biaya dalam penggunaan air dibangunan.

\section{Sistem Utilitas Bangunan Pintar Aspek Transportasi}

Pada bangunan UMN terdapat empat buah lift sebagai alat transportasi vertical. System yang diterapkan pada lift gedung UMN ini yaitu system pengoperasian ganjil dan genap. Bangunan UMN gedung $C$ ini memiliki ketinggian 12 lantai dengan 1 basement. Banyaknya kapasitas mahasiswa atau pengguna gedung sehingga menumpuk antrian pada saat jam-jam beraktivitas digedung ini. sistem pengoperasian pada lift UMN berdasarkan ganjil dan genap. Lift 1 dan 2 dapat dioperasikan berhenti pada lantai Basement, 1, 2, 4, 6, 8,10, 12. Pada Lift 3 dan 4 dapat dioperasikan berhenti pada lantai Basement, 1, 2, 3, 5, 7, 9, 
11. Penerapan system ini dilakukan untuk membuat efektifitas dan kemudahan bagi pengguna bangunan dalam mengakses ruangan atau lantai yang dituju. Penerapan system transportasi vertical terlihat pada gambar 7

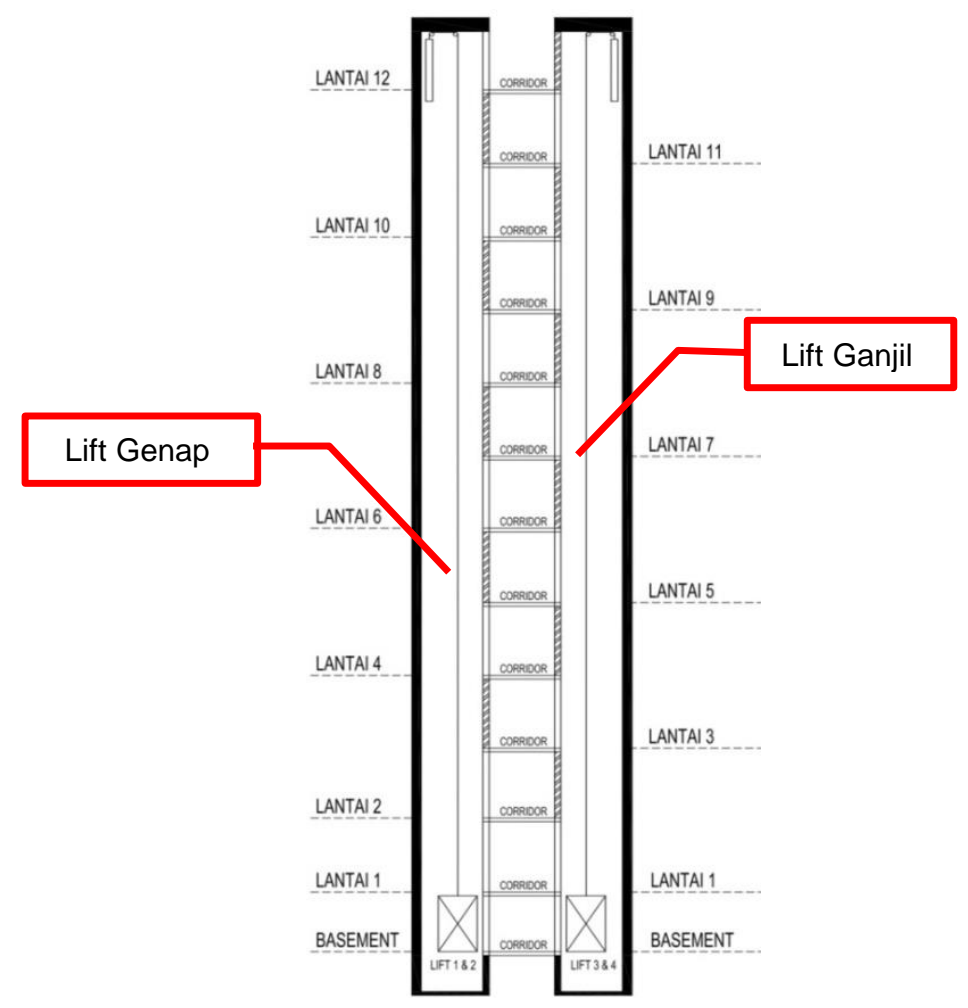

Gambar 7. Potongan Lift UMN Gedung C Sumber: Dokumen Pribadi, 2021

\section{Sistem Utilitas Bangunan Pintar Aspek Elektrikal}

Pada bangunan ini sumber daya listrik yang digunakan adalah sumber dari PLN dan memakai 2 genset dengan sistem pembakaran gas, dan sisa pembuangan gas tersebut digunakan untuk pendingin ruangan. PLN memiliki kapasitas daya yang terbatas sehingga ketika keadaan darurat generator set yang dilengkapi dengan automatic switch system yang secara otomatis. Distribusi listrik berasal dari PLN yang disalurkan ke gardu utama. pada tiap lantai terdapat ruang panel (hal ini dimaksudkan untuk memudahkan monitoring).

\section{Sistem Utilitas Bangunan Pintar Aspek Keamanan}

Universitas multimedia nusantara memiliki mesin absensi dan mesin pinjam buku yang berada diperpustakaan serta terintegrasi kedalam sebuah system kontrol. Dimana para mahasiswa menjadikan sebuah ID card atau kartu yang dimilikinya sebagai access card. Kartu tersebut bisa digunakan sebagai kartu untuk mengisi absensi dan digunakan sebagai kartu untuk meminjam buku pada perpustakaan kampus. Kartu yang di tapping pada mesin absensi atau manchine self service akan mentransfer data mahasiswa tersebut. Contohnya pada manchine self service, ketika mahasiswa menempelkan kartu identitasnya ke mesin data mahasiswa akan masuk dan termonitoring oleh sistem kemudian simpan buku pada mensin sensor untuk memverifikasi buku dan terakhir adalah bukti meminjam buku akan tercetak serta terinput oleh data. Hal ini memudahkan mahasiswa dalam meminjam buku sehingga tidak perlu mengantri untuk mengisi data secara manual. 
Pada bangunan ini dengan menjadikan kartu identitas sebagai akses memudahkan mahasiswa dalam beraktifitas dan menjadikan system keamanan dapat terkontrol dan termonitoring dengan baik dan terinput oleh system keamanan.

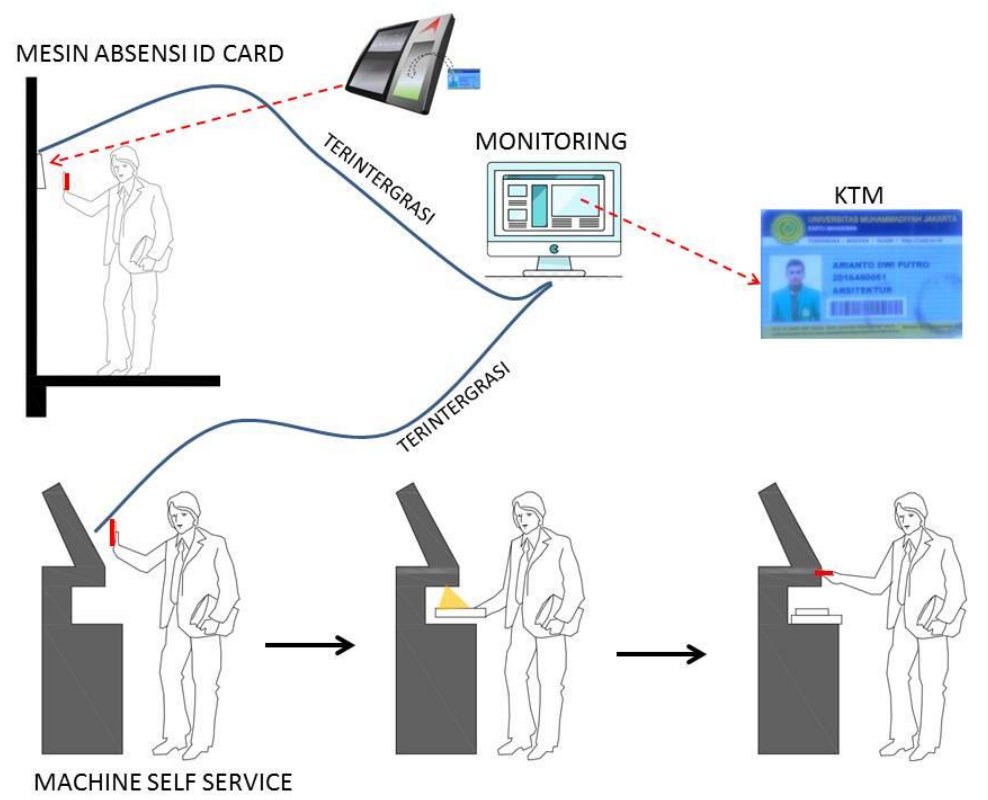

Gambar 8. Sistem RFID UMN

Sumber: Dokumen Pribadi, 2021

\section{Kesimpulan}

Berdasarkan Hasil analisis yang sudah dilakukan, Universitas Multimedia Nusantara menerapkan aspek-aspek bangunan pintar diantaranya

a. Sistem Utilitas Aspek Pencahayaan

b. Sistem Utilitas Aspek Penghawaan

c. Sistem Utilitas Aspek Pemipaan (Daur Ulang)

d. Sistem Utilitas AspekTransportasi

e. Sistem Utilitas Aspek Elektrikal

f. Sistem Utilitas Aspek Keamanan

Penerapan prinsip dari bangunan pintar tersebut menjadikan bangunan Universitas Multimedia Nusantara ini menjadi bangunan yang hemat energi dan berkelanjutan. Penerapan bangunan pintar juga terjadi melalui sistem sensor dan sistem otomasi bangunan contohnya sistem Access Card RFID serta Absensi. Selain itu penerapan yang dilakukan untuk menunjang bangunan dalam menjadikan bangunan yang hemat energi yaitu dengan pemanfaatan element-element alami seperti udara dan sinar matahari. Bangunan Universitas Multimedia mampu merespon hal tersebut dengan penerapan element-element arsitektural contohnya adalah secondary skin yang diterapkan pada facade-facade bangunan.

\section{Daftar Pustaka}

Buckman., Alex., Mayfield., M., \& Stephen Beck, .. (2014). Smart and Sustainable Built 
Environment.

https://www.researchgate.net/journal/20466099_Smart_and_Sustainable_Built_Envir onment.

Ching, Francis, D.K. (1993). Teori arsitektur. Jakarta: Erlangga.

FRANK, O. L. (2007). INTELLIGENT BUILDING CONCEPT: the challenges for building practitioners in the 21st century.

Froufe., M. M., Chinelli., C. K., Guedes., A. L., Haddad., A. N., Hammad., A. W., \& Soares., C. A. (2020). Smart Buildings: Systems and Drivers. www.mdpi.com/journal/buildings.

Ghaffarianhoseini, A., Berardi, U., AlWaer, H., Chang, S., Halawa, E., Ghaffarianhoseini, A., \& Clements-Croome, D. (2016). Analysis of recent interpretations from an international perspective.

Hakim. (2010). EVALUASI SISTEM BANGUNAN PINTAR PADA PUSAT PERBELANJAAN SENAYAN CITY DI JAKARTA. Arsitron Vol. 1 No. 2 Desember 2010.

Hoy., M. B. (2016). Smart Buildings: An Introduction to the Library of the. https://www. researchgate.net/publication/305073861.

Nissa, A., \& Donny, M. (2017). GLASS AND PERFORATED METAL DOUBLE SKIN FAÇADE PERFORMANCE IN HOT HUMID CLIMATE. Journal of Architecture and Built Environment.

Pramanik, P. K., \& Choudhury, P. (2018). IoT Data Processing: The Different Archetypes and their Security \& Privacy Assessments.

Pramanik, P. K., Pal, S., Brahmachari, A., \& Choudhury, P. (2018). Processing loT Data: From Cloud to Fog. It's Time to be Down-to-Earth.

Pramanik, P., Bulbul, M., Saurabh, P., Tanmoy, P., \& Simar, P. (2019). Green Smart Building:Requisites, Architecture,Challenges, and Use Cases. https://www.researchgate.net/publication/333784260.

Rahmawati, S. (2011). BNI 46 : SMART BUILDING.

Shaikh, P. H., Nor, N. B., \& Nallagownden, P. (2014). A review on optimized control systems for building energy and comfort management of smart sustainable buildings. Renewable \& Sustainable Energy Reviews,.

Sinopoli, J. (2010). Smart Buildings Systems for Architects, Owners and Builders. USA: elsevier.

Wibowo, S., Purwantiasning, A. W., \& Hantono, D. (2017). Penerapan Konsep Bangunan Pintar pada Perencanaan kantor Pusat Penelitian dan Pengembangan. Jurnal Arsitektur PURWARUPA. 